\title{
Promotion of Alcohol Production using high Gravity Fed-Batch Alcoholic Fermentation through Novel Yeast Strain
}

\author{
Govind misale $^{1,2}$, S. E. Neelgund ${ }^{1 *}$, S. V. Patil ${ }^{3}$, Vijendrasingh ${ }^{2}$ \\ ${ }^{1}$ Department of Biochemistry, Kuvempu University, Shankarghatta, Shivamogha-577451, Karnataka, India \\ ${ }^{2}$ Shree Renuka sugars Ltd., BC-105, Havlock Road, Cantonment, Belgaum-590003, Karnataka, India \\ ${ }^{3}$ Vasantdada Sugar Institute (VSI), Pune-412307, Maharashtra, India \\ *Corresponding Author: neelgund@gmail.com, Tel.: +91-9448234456
}

Available online at: www.isroset.org

Received: 29/Jun/2018, Accepted: 18/Aug2018, Online: 31/Dec/2018

\begin{abstract}
Fermentation is well known biological process to produce the alcohol by using raw materials as molasses, grains etc. The performance of molasses based distilleries are day by day improved towards high efficiency, lowest sugar loss and high yield. In many distilleries, earlier and at present the operation mode of fermentation process is "batch fermentation" which gives the less efficiency 80 to $85 \%$ with poor quality alcohol and spent wash generation is about 8 to 15 lit/lit of alcohol produced. Later on it is developed as "continuous fermentation" which gives high efficiency 88 to $90 \%$ and with better quality of alcohol and spent wash generation is about 3 to 4 lit/lit of alcohol produced by adopting spent wash recycle to fermenter and treatment of spent wash in integrated evaporation with distillation system. But In India distilleries effluent i.e., spent wash has high organic load which causes Major water pollution so these industries are comes under "Red category" and it is necessary to improve this process and reduce the spent wash generation as much as possible along with high fermentation efficiency and less energy consumption for separation of alcohol in downstream process of distilleries. So this presentation is to introduce the new mode of operation named as "High gravity Fed- batch alcoholic fermentation" of cane molasses. The pilot trial is taken by using the developed yeast stain "Scizosacharomyces Pombe-Fed" with upgraded feeding pattern. Process parameters are experimented and studied in "Shree Renuka Sugars Ltd. Havlaga unit" and the results high efficiency of about 89 to $90 \%$ and high yield of alcohol in fermented wash of about 11.8 to $12.5 \%$ so as to reduce the spent wash generation is about 2.2 to 2.4 lit/lit of alcohol produced which will helps to achieve one of the strict norm of Pollution Control board "Zero liquid Discharge" with post treatment of Bio-composting and incineration of high brix spent wash(55 to $60 \%$ Solids) in specially designed boiler.
\end{abstract}

Keywords - Batch fermentation, continuous fermentation, Fed- batch fermentation yeast microorganism, Zero liquid discharge, Red category.

\section{INTRODUCTION}

In India most of the molasses distilleries are producing alcohol total installed capacity is 4230 million lit per Annam 2016 ${ }^{1}$. Fermentation process is the upstream biological process of alcohol production and it is carried out in many mode of operation like batch, cascade continuous, (low gravity media) in which the sugar source is diluted and maintained the moderate sugar concentration in the media nearly about 7 to $8 \% \mathrm{v} / \mathrm{v}$ depends on the mode of operation. (4)The fermented broth containing low Alcohol concentration not only makes the alcohol is extracted by distillation highly energy-intensive, but also generates more effluent generation that needs to be treated by multistage evaporation, costing even more energy. As a result, many attempts have been made to achieve higher $\mathrm{Al} \%$ concentration at the end of fermentation, High gravity (HG) alcoholic fermentation technologies were proposed in the earlier and applied which made the Al\% concentration at the end of fermentation increase up to 10 to $11 \%$.(2,5) But the variations observed that increasing in the residual sugar level at the end of the fermentation, which will increases raw material consumption, \& also increase the difficulties of process control if the developments have not been done 2

Research in yeast physiology has revealed that many strains can tolerate far higher ethanol concentration usually without any conditioning or genetic modifications that risk making the modified strains lose some of their original Characteristics ${ }^{3}$. Therefore, high gravity (HG) Alcoholic fermentation technologies using media containing sugar of about $22 \%$ in order to achieve more than $12 \%$ (v/v) $\mathrm{Al} \%$. As the cost of fuel ethanol production is mainly from raw 
material consumption the residual sugar at the end of fermentation is strictly controlled at a level of 1.5 to $2 \%$ in industry.

\section{RELATED WORK}

To evaluate alcohol production using high gravity fed-batch alcoholic fermentation through novel yeast strain.

\section{METHODOLOGY}

Many microorganisms being exploited for alcohol production, the genus of Saccharomyces cerevisiae, Zymomonus mobilis schizosaccharomyces pombe etc. Currently, either alcoholic beverage or industrial fuel, is being produced by fermentation using the above strains. Acclimatization of the yeast strain was done in laboratory scale at high alcohol concentration 12 to $13 \%$ and high osmotic pressure, and high sugar concentration $18-20 \%$ the same strain is used for the new mode of operation I.e. improved "High gravity fed-batch alcoholic fermentation" and the stain most intensively developed species because it possesses some "superior characteristics" compared to above strains. Initially parent yeast is used to prepare the culture in lab stage of $50 \mathrm{ml}$ volume of diluted molasses medium of Specific gravity 1.050 with addition of nutrients as urea 40 to $50 \mathrm{ppm}$ as nitrogen source. Acclimatization of the parent yeast is done adopting the yeast culture in 5Lit capacity of small scale culture vessel in laboratory with high gravity medium up to media Sp. Gr 1.090. With this Acclimatized stain of "Scizosacharomyces Pombe-Fed" we have done trial in large scale fermenters located at Shree Renuka sugars Ltd at Havlaga unit Karnataka India.

\section{Culture vessel setup:}

Set up was for the culture preparation vessels CV-1,CV2,CV-3 ,CV-4 and CV5 Capacity 50 lit, 450 lit, 4000 lit, and 40000 lit and 40000 lit respectively MOC SS 304 ,sterile aeration is provided by the air blower through HEPA filter and Micro filter. To set up the uniform medium the broth mixture and Central agitator, for cooling the media cooling water through jacket and PHE is provided.

\section{Fermentation system:}

Three identical fermenter (Bio-reactor) was established of capacity each 900m3 Diameter- $10.1 \mathrm{mtr}$ and Height-11.25 $\mathrm{mtr}$,Shape of fermenter is cylindrical with bottom coned, MOC- MS (Mild steel) Epoxy coated throughout the internal part of fermenter and the working volume is considered as $90-95 \%$ to the fermenter sterile aeration is provided through air sparger system by air blower of capacity $400 \mathrm{Nm} 3 / \mathrm{hr}$. and the mixing of the raw contents was done by circulating the media with pumping system at a rate of $500 \mathrm{~m} 3 / \mathrm{hr}$. and to maintain the temperature of wash at $32^{\circ} \mathrm{c}$ Plate heat exchanger provided to each fermenter with RTD sensor.

\section{Culture Preparation and pitching:}

The above acclimatized mother culture is used for the preparation of required quantity of inoculum at every stage of Culture preparation molasses media is sterilized up to $121^{\circ} \mathrm{C}$ for $15 \mathrm{~min}$ and cooled at up to $32^{\circ} \mathrm{C}$ and retention time of 12 to 16 hours the culture is transfer to next stage as inoculum and finally at the stage of CV-4 yeast Cell count of mother culture is maintained about 550 to 600 million cell $/ \mathrm{ml}$ with 98 to $100 \%$ vitality, Sp.gr of culture media is 1.024 to 1.028 yeast culture quantity $40 \mathrm{~m} 3$ is ready as mother culture for fermentation system.

\section{Buildup of fermenter with Developed seed Culture:}

In the fermentation process, the rate of fermentation is depends on the quality of raw material used normally " $\mathrm{A}$ " grade molasses is preferred of quality used in this trail is TRS 50 to $51 \%$ and UFS- $4.3 \%$, FS - 46 to $46.5 \%$, During the fermentation in glycolysis pathway under unfavorable conditions and parameters byproducts formation is observed like acetone, aldehyde, methane, higher alcohols namely iso-propyle alcohol amyl alcohol, iso-amyl alcohol etc. So it is necessary to maintain all parameters like optimum temperature of fermenter should be $32^{\circ} \mathrm{C}$ to $33^{\circ} \mathrm{C}$, $\mathrm{pH}$ range is 4.4 to 4.6 and is maintained with the dose of Sulfuric acid which will fulfill the additional benefit sulfur content as nutrient. Cell count of the fermenter is should be in the range of 450 to 500 million cells pr ml of sample. Sugar concentration is maintained not more than 12 to $14 \%$ so as to prevent osmotic stress on yeast cells. Sterilized air is to be provided by using HEPA and micro filter. Urea and DAP nutrient dosing is given about 40 to $50 \mathrm{ppm}$ for each batch as a nitrogen source by taking the precautions to avoid the contamination in culture preparation.

\section{Feeding and input methods of raw materials:}

Initially the fermenter is charged by the molasses and water media of sugar concentration maintained 7 to $8 \%$ and set up gravity 1.055 to 1.060 and level taken of about $30 \%$ of the fermenter working volume includes the simultaneous addition of seed culture $75 \mathrm{~m} 3$ at the feed rate $30 \mathrm{~m} 3$ / hour (9 to $10 \%$ of total volume).

$>$ RT of 3 hour gap is given to the fermenter to activate and improve the cell count of the culture in the low gravity medium.

After this RT feed gravity increased to 1.140 by adjusting the molasses and water feed up to 4 hours in between water feeding is stopped when Pre-calculated water quantity reaches.

After 4 hours of above feeding Increase the feed quantity of molasses by 15 to $20 \%$ by analysis so that the Sp. Gr of fermenter should not be above 1.090 and 
complete the molasses feeding same as per required alcohol \% i.e. 12 to $12.8 \%$ w.r.to TRS of molasses.

Aeration is stopped after completion of feeding i.e., up to 18 to 20 hours from the starting feed time.

$>$ The total feeding pattern is completed up to 18 to 20 hour by considering this feeding time to complete the fermentation of one fermenter RT is required 48 to 52 hours.

The total time taken to complete one batch including emptying of fermenter is 52 to 54 hours.

\section{RESULTS AND DISCUSSION}

During the trial of Fed- batch alcoholic fermentation of cane molasses below results are recorded with feed pattern. Process oscillations observed:

By the observation of initial batches we have given the molasses at feed alcohol $12.0 \%$ but due to the less cell count it is observed that the recovery is less. Then the culture feed is raised up to 70-75 $\mathrm{m} 3$ per fermenter i.e. 9$10 \%$ of total volume then the result was observed that cell count maintained 440 million cells per $\mathrm{ml}$ sample which has given the better result. Initially During completion of total feed the Sp. Gr of the fermenter is maintained 1.090 to 1.098 which causes the osmotic pressure due to high sugar concentration the cell growth rate is restricted so the rate of fermentation is reduced so the precaution was taken that sugar concentration in the feed is optimized and specific gravity is maintained not more than 1.084 then the better results are observed in the next batches. Due to less cell count the residual sugar range after completion of fermentation is raised to 2.5 to $2.9 \%$ at the initial batches so the culture quantity is raised up to $10 \%$ the range of residual sugar came down to 1.9 to $2.0 \%$ by this the alcohol recovery is increased.

Positive approaches and achieved results: Retention Time (HRT): The time taken to complete conversion of sugars to alcohol in the above mode of operation is 48 to 52 hours. In which the 18 to 20 hours are required to charge the fermenter. This time was the reduced by modified feed pattern keeping the all observations like cell count, sugar concentration alcohol yield and byproduct formation. These results are similar with the previous studies conducted ${ }^{2}$. Fermentation Efficiency: Initially we have got the fermentation efficiency 83 to $85 \%$ because of sugar loss and culture pitching quantity was less because of this the desired $\mathrm{A} 1 \%$ was not achieved to minimize the loss of sugar culture pitching quantity is increased and aeration time was increased up to 20 to 22 hours.

Recovery and yield: As per the theoretical calculation by analyzing the sugar content in the cane molasses the recovery of alcohol matches, in practical as per above parameters it is observed that there is no recovery loss in this mode of operation.

Residual Sugars: After the Retention time of 52 to 54 hours the residual content in the fermented broth is about 1.8 to $1.9 \%$ which indicates the negligible sugar (un-fermentable sugars) loss in this mode of operation.

Less energy consumption: At high alcohol concentration $(12-13 \%)$ fermented wash required to achieve the installed plant capacity is less so the heat energy required in downstream process to extract the alcohol is less.

Chemical consumption: During the fermentation to control the foaming anti foam agent required is minimized up to $40 \%$.

Less Effluent Generation and its parameters: Spent wash generation in the continuous mode of operation is 3.5 to 4 lit/lit (40 to $45 \%$ solids) of alcohol produced even by adopting the evaporation treatment and without evaporation it is 7.5 to $8 \mathrm{lit} /$ lit (16 to $18 \%$ solids) of alcohol by counting the $20 \%$ recycle of spent wash to fermentation. By the "High gravity fed-batch alcoholic fermentation" mode of operation basically the alcohol produced is 12 to $12.8 \%$ so the fermented wash required to reach the plant capacity is $30 \%$ less as compared with continuous mode of operation. So initially the effluent produced after distillation the generation of effluent is $30 \%$ less so we have achieved the 2.2 to $2.4 \mathrm{lit} /$ lit (55 to $60 \%$ solids) of alcohol produced with adopting the integrated evaporation and forced circulation evaporation system and without evaporation 5.7 to $5.8 \mathrm{lit} / \mathrm{lit}$ of alcohol produced( 20 to 22 $\%$ solids )by taking an example of 120 KLPD distillery can treat its spent wash is about $1.5 \mathrm{lit} / \mathrm{lit}$ less in this mode of operation so the cost for treatment of effluent treatment is reduced up to $30 \%$.

Feeding pattern and observation of process parameters \& its descriptions.

As per the pilot trails the result and feed pattern details given below.

Initially during the first 3 hours feeding it is observed that the growth rate of the yeast cells are enhanced by feeding the molasses and water media having the sugar concentration 10 to $12 \%$ with dosing of nutrients of nitrogen source with sterile aeration. In the next step of feeding 3 hours retention is given so as to achieve the desired cell count about 420 to 450 million cells $/ \mathrm{ml}$.

After RT the molasses feed and water feed is given at set up Sp. Gr 1.140 up to 4hours so that the growth rate is increased by aerobic respiration simultaneously an aerobic fermentation also done because of high set up gravity feed 
${ }^{4}$. During this period the analysis shows that specific gravity and residual sugars are increased up to 1.081 and $5.9 \%$ respectively.

In the next step of feeding as per analyzed parameters, molasses and water quantity was adjusted so that the optimum osmotic pressure is maintained because if it is high then the yeast activity is reduced and rate of fermentation is affected ${ }^{5}$. After 22 hours aeration is stopped it Leeds to perform the anaerobic alcoholic fermentation to get the desired $\mathrm{Al} \%$ and it is observed that 12 to $12.5 \%$ alcohol is achieved by this mode of operation.

\section{CONCLUSION AND Future SCOPE}

This is the developed process regarding High gravity fedbatch alcoholic fermentation, based on the results achieved by the use of developed stain "Scizosacharomyces PombeFed" and upgraded process feeding pattern, it is concluded that we can run the large scale distilleries more than 200 KLPD by minimizing the heat energy requirement ,less cost of equipment maintenance, no recovery loss and can achieve easily "Zero liquid discharge" by post treatment like Biocamposting and incineration of effluent in boiler.

Table 1. Trial results and feed pattern of fed-batch fermentation.

\begin{tabular}{|c|c|c|c|c|c|c|c|c|c|c|}
\hline \multicolumn{11}{|c|}{ Detailed analysis Report of fed-batch fermentation. } \\
\hline $\begin{array}{c}\text { No of } \\
\text { Batche } \\
\quad \text { s }\end{array}$ & $\begin{array}{c}\text { Molasses } \\
\text { used in } \\
\text { MT }\end{array}$ & $\begin{array}{c}\text { Wate } \\
\mathbf{r} \\
\text { used } \\
\text { in } \mathbf{m 3}\end{array}$ & $\begin{array}{l}\text { Culture } \\
\text { pitchin } \\
\mathrm{g} \text { in } \mathrm{m} 3\end{array}$ & $\begin{array}{c}\text { Sp. Gr } \\
\text { after } \\
\text { molasses } \\
\text { feeding } \\
\text { completion }\end{array}$ & $\begin{array}{c}\text { Final } \\
\text { gravit } \\
\mathbf{y}\end{array}$ & $\begin{array}{c}\text { Alcohol } \\
\text { content } \\
\%\end{array}$ & $\begin{array}{l}\text { Residu } \\
\text { al } \\
\text { sugars }\end{array}$ & $\begin{array}{c}\text { Observed } \\
\text { recovery } \\
\text { lit/MT } \\
\text { Molasses }\end{array}$ & $\begin{array}{l}\text { Fermentatio } \\
\text { n Efficiency }\end{array}$ & $\begin{array}{c}\text { Retention } \\
\text { time }\end{array}$ \\
\hline 1 & 392 & 478 & 65 & 1.091 & 1.061 & 11.6 & 2.4 & 248 & 83.37 & 52 \\
\hline 2 & 384 & 480 & 67 & 1.088 & 1.059 & 11.7 & 2.2 & 254 & 85.31 & 50 \\
\hline 3 & 384 & 480 & 65 & 1.084 & 1.056 & 11.7 & 2.1 & 254 & 85.36 & 48 \\
\hline 4 & 384 & 480 & 65 & 1.082 & 1.054 & 11.6 & 2.3 & 251 & 84.11 & 50 \\
\hline 5 & 370 & 480 & 64 & 1.080 & 1.058 & 11.5 & 2.1 & 256 & 86.01 & 50 \\
\hline 6 & 370 & 475 & 62 & 1.075 & 1.060 & 11.5 & 2.2 & 252 & 84.72 & 54 \\
\hline 7 & 370 & 477 & 65 & 1.100 & 1.066 & 11.3 & 2.17 & 250 & 83.77 & 54 \\
\hline 8 & 383 & 482 & 70 & 1.075 & 1.056 & 12.05 & 1.98 & 262 & 87.81 & 52 \\
\hline 9 & 368 & 481 & 70 & 1.078 & 1.057 & 11.8 & 2.01 & 266 & 89.27 & 52 \\
\hline 10 & 374 & 479 & 70 & 1.079 & 1.054 & 11.9 & 1.96 & 263 & 88.41 & 50 \\
\hline 14 & 377 & 482 & 70 & 1.078 & 1.052 & 12.00 & 1.90 & 267 & 89.46 & 52 \\
\hline 15 & 392 & 479 & 65 & 1.095 & 1.060 & 12.28 & 2.9 & 263 & 88.37 & 50 \\
\hline 16 & 377 & 480 & 70 & 1.080 & 1.050 & 12.50 & 1.94 & 279 & 89.68 & 48 \\
\hline 17 & 383 & 481 & 70 & 1.078 & 1.053 & 12.80 & 1.86 & 281 & 90.55 & 50 \\
\hline 18 & 386 & 484 & 71 & 1.080 & 1.053 & 12.60 & 1.98 & 277 & 89.22 & 50 \\
\hline 19 & 386 & 480 & 70 & 1.079 & 1.055 & 12.80 & 1.90 & 280 & 89.98 & 52 \\
\hline 20 & 383 & 486 & 72 & 1.079 & 1.058 & 12.40 & 1.96 & 274 & 88.15 & 50 \\
\hline 21 & 380 & 480 & 73 & 1.078 & 1.052 & 12.70 & 1.92 & 282 & 90.64 & 50 \\
\hline 22 & 381 & 480 & 70 & 1.080 & 1.053 & 12.72 & 1.80 & 281 & 90.32 & 48 \\
\hline 23 & 386 & 480 & 72 & 1.085 & 1.054 & 12.70 & 1.86 & 276 & 88.95 & 50 \\
\hline 24 & 386 & 480 & 75 & 1.078 & 1.053 & 12.80 & 1.96 & 280 & 89.98 & 48 \\
\hline 25 & 383 & 480 & 73 & 1.078 & 1.054 & 12.80 & 1.98 & 281 & 90.44 & 48 \\
\hline 26 & 378 & 480 & 75 & 1.080 & 1.056 & 12.70 & 1.89 & 283 & 90.98 & 50 \\
\hline 27 & 381 & 480 & 77 & 1.082 & 1.054 & 12.80 & 1.94 & 284 & 91.23 & 48 \\
\hline
\end{tabular}


Table No 2. Raw material feeding patterns and analysis results of fed batch fermentation

\begin{tabular}{|c|c|c|c|c|c|c|c|c|}
\hline \multicolumn{9}{|c|}{ Feed pattern of $900 \mathrm{~m} 3$ capacity fermenter and its results } \\
\hline Time in hrs. & $\begin{array}{l}\text { Culture } \\
\text { Qty. }\end{array}$ & $\begin{array}{l}\text { Molasses } \\
\text { feed }\end{array}$ & Water feed & $\begin{array}{l}\text { Specific } \\
\text { gravity }\end{array}$ & $\begin{array}{l}\text { Residual } \\
\text { sugars \% }\end{array}$ & $\begin{array}{l}\text { Cell count } \\
\text { million } / \mathrm{ml}\end{array}$ & $\begin{array}{l}\text { Viable } \\
\text { cells \% }\end{array}$ & $\begin{array}{l}\text { Al } \\
\%\end{array}$ \\
\hline Up to 3 hrs. & $\begin{array}{l}\text { 75m3@25 } \\
\text { m3 / hrs. }\end{array}$ & $\begin{array}{l}52 \text { Ton@ } \\
17.5 \text { Ton / } \\
\text { hrs. }\end{array}$ & $\begin{array}{l}150 \mathrm{~m} 3 @ \\
50 \mathrm{~m} 3 / \mathrm{hrs} .\end{array}$ & 1.066 & $\mathrm{NE}$ & 290 & 90 & $\mathrm{NE}$ \\
\hline 3 to 6 hrs. & \multicolumn{3}{|c|}{$\begin{array}{l}3 \text { hour RT is given with aeration continuous } \\
\text { at rate } 400 \mathrm{Nm} 3 / \mathrm{hrs} \text {. }\end{array}$} & 1.051 & 4.1 & 390 & 85 & $\mathrm{NE}$ \\
\hline 6 to $10 \mathrm{hrs}$. & -- & $\begin{array}{l}82 \text { Ton@ } \\
20.5 \text { Ton / } \\
\text { hrs. }\end{array}$ & $\begin{array}{l}120 \mathrm{~m} 3 @ \\
30 \mathrm{~m} 3 / \mathrm{hrs} .\end{array}$ & 1.065 & 5.2 & 410 & 85 & 6.4 \\
\hline 10 to 20 hrs. & -- & $\begin{array}{lr}116 \quad \text { ton } \\
@ 23.5 \text { Ton } \\
\text { / hrs. }\end{array}$ & $\begin{array}{l}\text { 210M3 @ } \\
\text { 30m3/ hrs. }\end{array}$ & 1.081 & 5.9 & 430 & 82 & 7.1 \\
\hline & \multicolumn{8}{|c|}{ Aeration is stopped to boost the anaerobic alcoholic fermentation } \\
\hline After 24 hrs. & \multicolumn{3}{|c|}{ Under Retention } & 1.076 & 4.4 & 430 & 80 & 8.9 \\
\hline After 32 hrs. & \multicolumn{3}{|c|}{ Under Retention } & 1.069 & 4.01 & 380 & 75 & 9.4 \\
\hline After $40 \mathrm{hrs}$. & \multicolumn{3}{|c|}{ Under Retention } & 1.061 & 3.5 & 360 & 73 & 10.8 \\
\hline After 48 hrs. & \multicolumn{3}{|c|}{ Under Retention } & 1.057 & 3.1 & 330 & 70 & 11.8 \\
\hline After 52 hrs. & \multicolumn{3}{|c|}{ Under Retention } & 1.052 & 1.9 & 240 & 70 & 12.6 \\
\hline
\end{tabular}

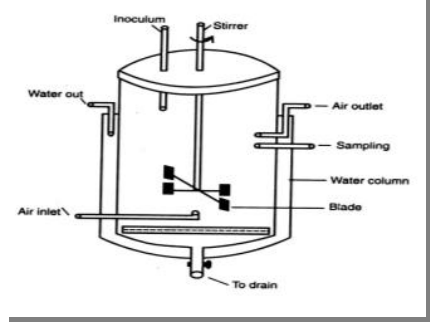

Figure 1. Schematic diagram of fermenter.

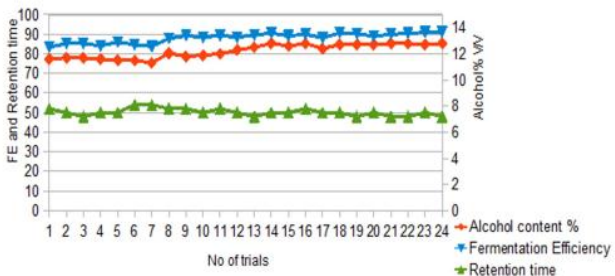

Figure 2. Graphical representation of no of trial in fed-batch alcoholic fermentation.

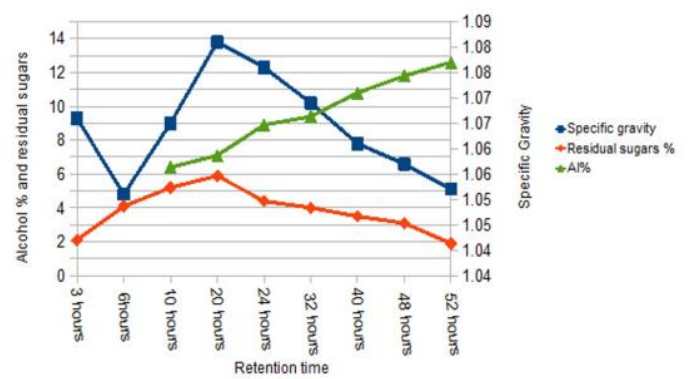

Figure 3. Graphical presentation Variation of Parameters during the fed batch alcoholic fermentation. 


\section{REFERENCES}

[1]. Opportunities for green chemistry initiatives: molasses based distilleries office of principal scientific adviser to the Goi vigyan bhawan annexe, New Delhi - 1100112014 (4, 5)

[2]. Process oscillations in continuous ethanol fermentation -Guofeng Bai from 9 to 13 .

[3]. Ethanol tolerance of some yeasts by B. Ranganathan and J.V Bhat, (Fermentation Technology Laboratory, Indian Institute of Science, Bangalore-3) (105-110)

[4]. Overview of continuous alcohol fermentation and multipressure distillation technology Author: G B DESHPANDE Praj Industries Ltd, Bavdhan, Pune - 411 021, India (577-578)

[5]. V. Ansanay-Galeote, B. Blondin, S. Dequin, and J. Sablayrolles, "Stress effect of ethanol on fermentation kinetics by stationaryphase cells of Saccharomyces cerevisiae," 677-681, 2001.

\section{AUTHORS PROFILE}

Govind P. Misale.

Associate Vice President (Ethanol) Renuka Sugars limited. Belgaum. Mr. Govind has vast experience in fermentation and distillation of ethanol.

Prof (Dr) S. E Neelgund

Professor, Department of Biochemistry, Kuvempu University. Shimoga. He is having experience in Biological Sciences and done is Post-Doctoral Fellowship in USA.

Vijendra Singh

Executive Director Shree Renuka Sugars Limited. Mumbai. $\mathrm{He}$ bears vast experience in Sugar, power and ethanol Production and in all type of fermentation.

Dr S. V. Patil

Head Alcohol technology Vasant dada Sugar Institute Pune. He has presented many papers on fermentation
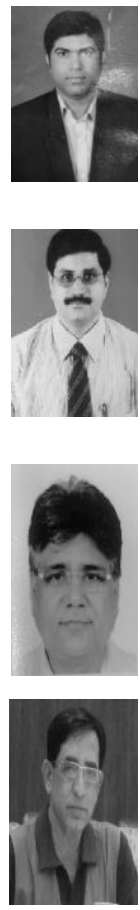